\title{
Parametric Study of Entropy Generation in a Fluid with Internal Heat Generation between Two Rotating Cylinders Subjected to Convective Cooling at the Surface
}

\author{
M. El Haj Assad ${ }^{1}$ and Hakan F. Oztop ${ }^{2}$ \\ ${ }^{1}$ Department of Energy Technology, School of Science and Technology, Aalto University, P.O. Box 11400, 00076 Aalto, Finland \\ ${ }^{2}$ Department of Mechanical Engineering, Faculty of Technology, Firat University, 23119 Elazig, Turkey
}

Correspondence should be addressed to M. El Haj Assad, mamdouh.assad@aalto.fi

Received 18 October 2012; Accepted 5 November 2012

Academic Editors: C.-T. Hsieh and P. L. Maffettone

Copyright (C) 2012 M. El Haj Assad and H. F. Oztop. This is an open access article distributed under the Creative Commons Attribution License, which permits unrestricted use, distribution, and reproduction in any medium, provided the original work is properly cited.

\begin{abstract}
Entropy generation analysis of a steady fluid flow with internal heat generation between two rotating cylinders was presented. The surface of the inner cylinder was kept at constant temperature while the surface of the outer cylinder was exposed to convection cooling. Analytical expressions for velocity and temperature distributions within the fluid were obtained. The effects of velocity ratio, Biot number, Brinkman number and other dimensionless parameters on the temperature distribution and local and total entropy generation rates were investigated and the results were presented graphically.
\end{abstract}

\section{Introduction}

Heat transfer analysis in annuli with rotating inner and outer cylinders is an important research field and has a wide range of many engineering applications such as swirl nozzles, commercial viscometers, journal bearings, chemical mixing devices, and electric motors.

Entropy generation and its minimization have been considered as an effective tool to improve the performance of any heat transfer process. Entropy generation minimization of diabatic distillation column with trays has been investigated using a new approach [1] in which the exchanged heat has been considered as a control variable instead of temperature. A numerical study of mixed convection and entropy generation in Poiseulle-Benard channel in different angles has been presented [2]. A numerical study of entropy generation using $3 \mathrm{D}$ in the case of liquid metal laminar natural convection in a differentially heated cubic cavity and in the presence of an external magnetic field orthogonal to the isothermal walls has been carried out [3]. A numerical analysis has been presented to study laminar-forced convection and entropy generation in a helical coil with constant wall heat flux [4] where optimal Reynolds numbers were found to be related to the wall heat flux. Entropy generation analysis has been applied to a natural convection cooling of heat source mounted inside a cavity [5]. Second law analysis has been used to obtain analytically the entropy generation for a laminar flow in semicylindrical ducts subjected to constant wall heat flux [6]. Entropy generation due to convection and conduction mode of heat transfer (conjugate natural convection) in enclosures bounded by vertical solid walls with different thicknesses has been studied [7]. Entropy generation has been obtained analytically by using second law analysis for a laminar flow in rectangular ducts with semicircular ends [8]. In the analysis [8], the effects of constant wall heat flux and constant wall temperature as boundary conditions have been studied.

Entropy generation analysis in an annuli flow with inner cylinder at rest, and rotating outer cylinder has been presented [9] where the entropy generation in the system due to the heat transfer has been considered and the entropy generation due to fluid friction has been neglected. An experimental study of heating fluid between two concentrating cylinders with cavities with rotating inner cylinder and outer cylinder at rest has been conducted [10]. Entropy generation for nonlinear viscoelastic fluid in concentric rotating cylinders 
subjected to different boundary conditions has been investigated [11] in which the results show that entropy generation number increases with increasing Brinkman number. The problem of natural convection of gas in an annulus between two horizontal coaxial cylinders at rest with uniform internal heat generation and different temperatures at the boundaries has been introduced and investigated numerically [12]. The effect of variable viscosity of fluid flow on entropy generation between two concentric cylinders at rest with a convective cooling at the outer cylinder has been investigated [13]. Entropy generation analysis inside concentric annuli with relative rotation has been presented [14] without investigating the effect of internal heat generation within the fluid and without considering the exact fluid temperature in calculating the entropy generation rate. More research studies related to entropy generation can be found in the literature [15-18].

As can be seen from the above research works related to annular flow between two rotating cylinders, the effect of internal heat generation on local and total entropy generation rates has not yet been investigated in the literature and this study is considered as a first approach to consider that effect.

\section{Mathematical Formulation}

In this section, We developed a mathematical model for the flow and thermal characteristics of a fluid between two rotating cylinders which rotate in the same direction. The schematic diagram of the physical problem is illustrated in Figure 1. It is assumed that the fluid thermal properties are temperature independent. The flow considered in the present is one-dimensional, steady, laminar and purely tangential. The radius of the inner cylinder is $r_{1}$ and of the outer cylinder is $r_{2}$. It is assumed that the outer cylinder wall thickness is negligible and has the same thermal conductivity as that of the fluid. The inner and the outer cylinders are rotating at angular velocities $\omega_{1}$ and $\omega_{2}$, respectively. The inner fluid surface is kept at temperature $T_{1}$ while the outer surface is subjected to convection by a coolant at temperature $T_{\infty}$.

2.1. Velocity Distribution. Under the above flow conditions, the momentum equation can be written as

$$
\frac{d^{2} v_{\theta}}{d r^{2}}+\frac{1}{r} \frac{d v_{\theta}}{d r}-\frac{v_{\theta}}{r^{2}}=0
$$

where $v_{\theta}$ is the tangential velocity. The boundary conditions are

$$
\begin{aligned}
& \text { at } r=r_{1}: v_{\theta}=v_{1}=\omega_{1} r_{1}, \\
& \text { at } r=r_{2}: v_{\theta}=v_{2}=\omega_{2} r_{2} .
\end{aligned}
$$

Consider the following dimensionless parameters:

$$
w=\frac{v_{2}}{v_{1}}, \quad R=\frac{r}{r_{1}}, \quad z=\frac{r_{2}}{r_{1}}, \quad V=\frac{v_{\theta}}{v_{1}} .
$$

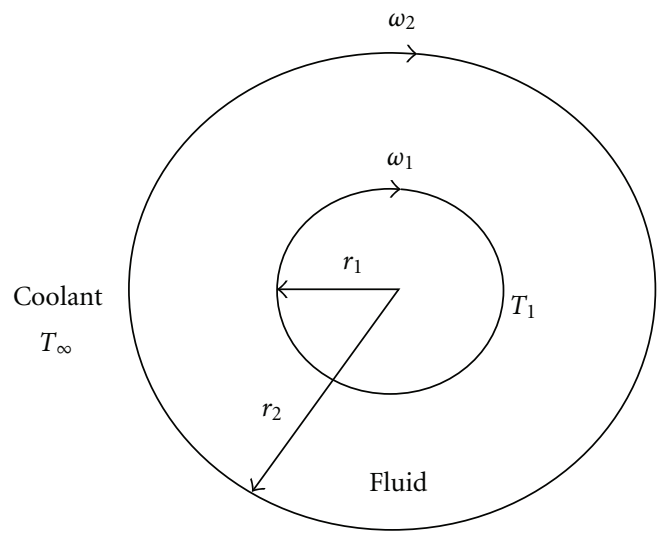

FIGURE 1: Schematic diagram of concentric rotating annuli.

The momentum equation of (1) can be written in a dimensionless form as

$$
\frac{d^{2} V}{d R^{2}}+\frac{1}{R} \frac{d V}{d R}-\frac{V}{R^{2}}=0 .
$$

Consider the following dimensionless boundary conditions:

$$
\begin{aligned}
& V(R=1)=1, \\
& V(R=z)=w .
\end{aligned}
$$

The solution of (5) subjected to the boundary conditions in (6) is obtained as

$$
V=\frac{z^{2}-R^{2}+w z R^{2}-w z}{R\left(z^{2}-1\right)} .
$$

2.2. Temperature Distribution. The energy equation of the fluid with internal heat generation between the two rotating cylinders can be expressed as

$$
\frac{1}{r} \frac{d}{d r}\left(r \lambda \frac{d T}{d r}\right)+\dot{q}+\mu \phi=0,
$$

where $\dot{q}$ is the internal heat generation, $\lambda$ is the thermal conductivity, $\mu$ is the dynamic viscosity, and $\phi$ is the viscous dissipation. The viscous dissipation is

$$
\phi=\left[r \frac{d}{d r}\left(\frac{v_{\theta}}{r}\right)\right]^{2} .
$$

The thermal boundary conditions are

$$
\begin{gathered}
T\left(r=r_{1}\right)=T_{1}, \\
-\lambda\left(\frac{d T}{d r}\right)_{r=r_{2}}=\alpha\left[T\left(r=r_{2}\right)-T_{\infty}\right],
\end{gathered}
$$

where $\alpha$ is the convection heat transfer coefficient. In order to express (8) in a dimensionless form, the following dimensionless parameters are introduced as

$$
\theta=\frac{T-T_{\infty}}{T_{1}-T_{\infty}}, \quad \mathrm{Bi}=\frac{\alpha r_{2}}{\lambda}, \quad \operatorname{Pr}=\frac{\mu c_{p}}{\lambda},
$$

$$
\mathrm{Ec}=\frac{v_{1}^{2}}{c_{p}\left(T_{1}-T_{\infty}\right)}, \quad \mathrm{Br}=\operatorname{PrEc}, \quad Q=\frac{\dot{q} r_{1}^{2}}{\lambda\left(T_{1}-T_{\infty}\right)},
$$




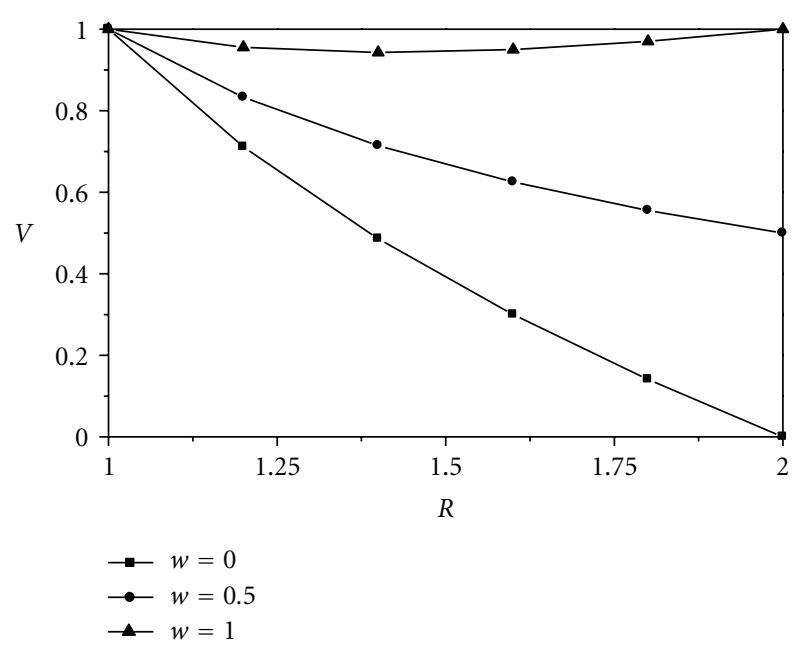

(a)

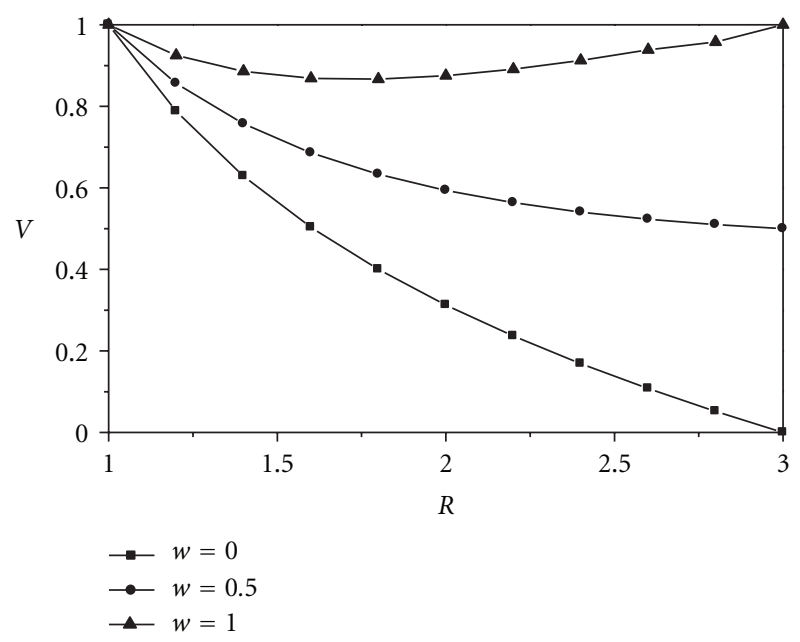

(b)

Figure 2: Velocity distribution ((a) $z=1$; (b) $z=3$ ).

where $\mathrm{Bi}$ is the Biot number, $\mathrm{Br}$ is the Brinkman number, Ec is the Eckert number, $\operatorname{Pr}$ is the Prandtl number, $Q$ is the dimensionless internal heat generation, and $c_{p}$ is the specific thermal capacity. Using the parameters of (11), (8) can be rewritten as

$$
\frac{d^{2} \theta}{d R^{2}}+\frac{1}{R} \frac{d \theta}{d R}=-Q-\operatorname{Br}\left[\frac{d V}{d R}-\frac{V}{R}\right]^{2},
$$

with the dimensionless thermal boundary conditions as

$$
\begin{gathered}
\theta(R=1)=1, \\
\left(\frac{d \theta}{d R}\right)_{R=z}=-\frac{B i}{z} \theta(R=z) .
\end{gathered}
$$

The solution of (12) can be obtained as

$$
\theta=-\frac{Q}{4} R^{2}-\frac{D^{2} \mathrm{Br}}{4 R^{2}}+C_{1} \ln (R)+C_{2},
$$

where

$$
\begin{gathered}
C_{1}=\frac{-\mathrm{Bi}\left[-(Q / 4) z^{2}-D^{2} \mathrm{Br} / 4 z^{2}+D^{2} \mathrm{Br} / 4+Q / 4+1\right]}{1+\mathrm{Bi} \ln (z)} \\
+\frac{(Q / 2) z^{2}-D^{2} \mathrm{Br} / 2 z^{2}}{1+\mathrm{Bi} \ln (z)} \\
C_{2}=1+\frac{Q}{4}+\frac{D^{2} \mathrm{Br}}{4} \\
D=\frac{2 z(w-z)}{z^{2}-1} .
\end{gathered}
$$

\section{Entropy Generation Analysis}

The local entropy generation rate due to fluid temperature gradient and fluid friction (viscous dissipation) is given as [19]

$$
\dot{S}^{\prime \prime \prime}=\frac{\lambda}{T^{2}}\left(\frac{d T}{d r}\right)^{2}+\frac{\mu}{T}\left[r \frac{d}{d r}\left(\frac{v_{\theta}}{r}\right)\right]^{2} .
$$

The first term of (18) corresponds to the heat transfer irreversibility and the second term corresponds to the irreversibility due to viscous dissipation. Equation (18) considers the exact local temperature of the fluid obtained by (14). Using the dimensionless parameters defined in (4) and (11), the entropy generation number can be obtained from (2) as

$$
\begin{aligned}
N_{s}= & \frac{r_{1}^{2} \dot{S}^{\prime \prime \prime}}{\lambda} \\
= & \frac{1}{(\theta+t /(1-t))^{2}}\left(\frac{d \theta}{d R}\right)^{2} \\
& +\frac{\mathrm{Br}}{(\theta+t /(1-t))}\left[\frac{d V}{d R}-\frac{V}{R}\right]^{2},
\end{aligned}
$$

where $t=T_{\infty} / T_{1}$ is the temperature ratio of the coolant fluid to the inner cylinder surface temperature. The total entropy generation is expressed as

$$
\dot{S}=\int_{A} \dot{S}^{\prime \prime \prime} L d A
$$

where $A$ is the cross-sectional area of the gab between the cylinders and $L$ is the length of the rotating cylinders. Substituting (19) into (20), the total entropy generation rate can be obtained as

$$
\dot{S}=\frac{2 \pi \lambda L}{r_{1}^{2}} \int_{r_{1}}^{r_{2}} N_{s} r d r
$$

Equation (21) can be written in a dimensionless form as

$$
N_{t}=\frac{\dot{S}}{2 \pi \lambda L}=\int_{1}^{z} N_{s} R d R
$$

where $N_{t}$ is the dimensionless total entropy generation rate. 


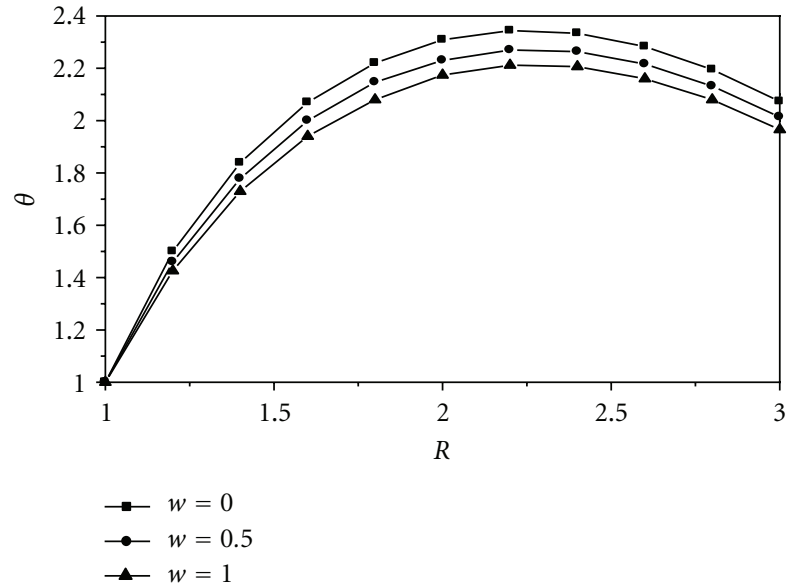

(a)

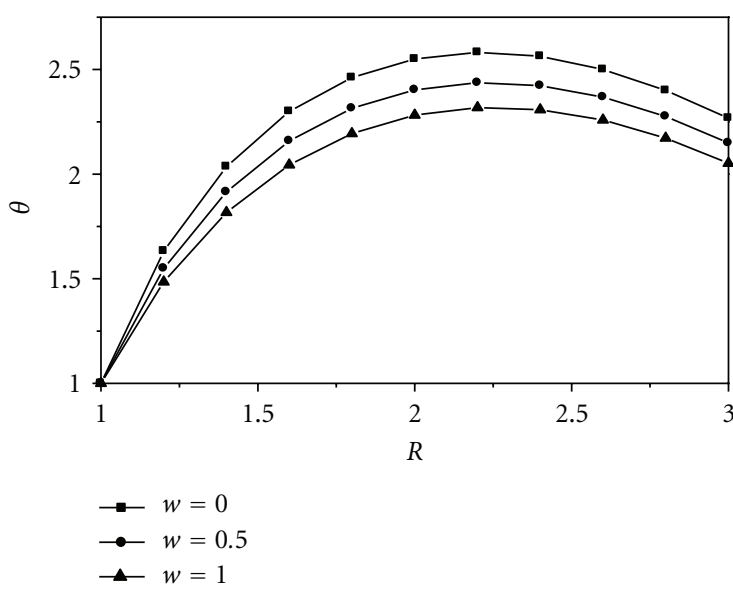

(b)

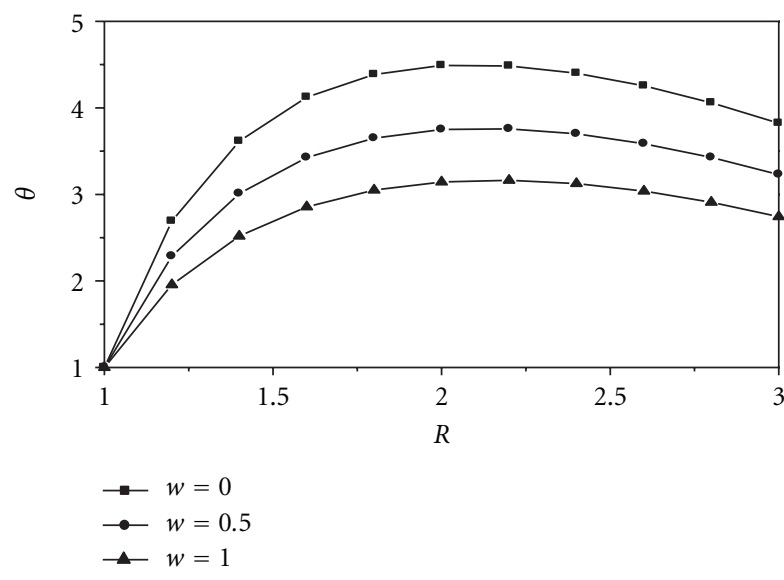

(c)

Figure 3: Temperature distribution ((a) $\mathrm{Br}=0.5$; (b) $\mathrm{Br}=1$; (c) $\mathrm{Br}=5)$.

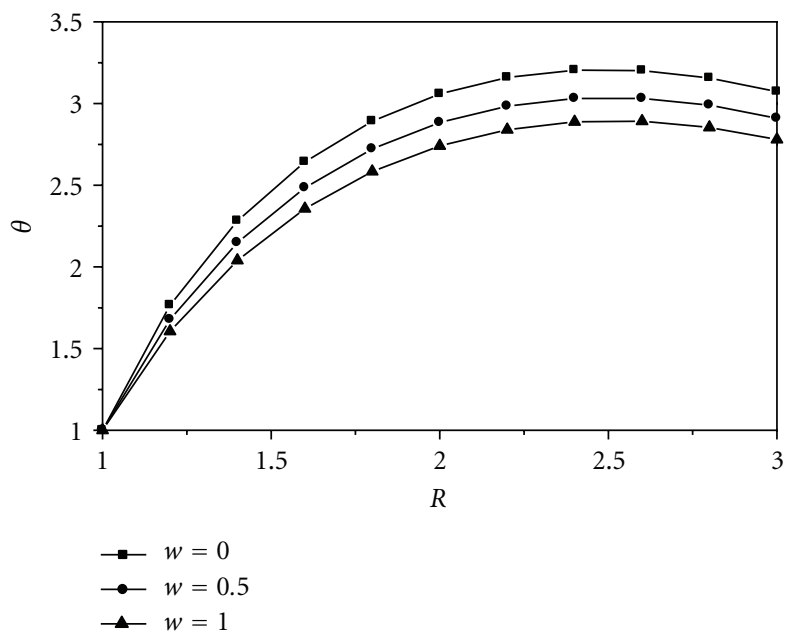

(a)

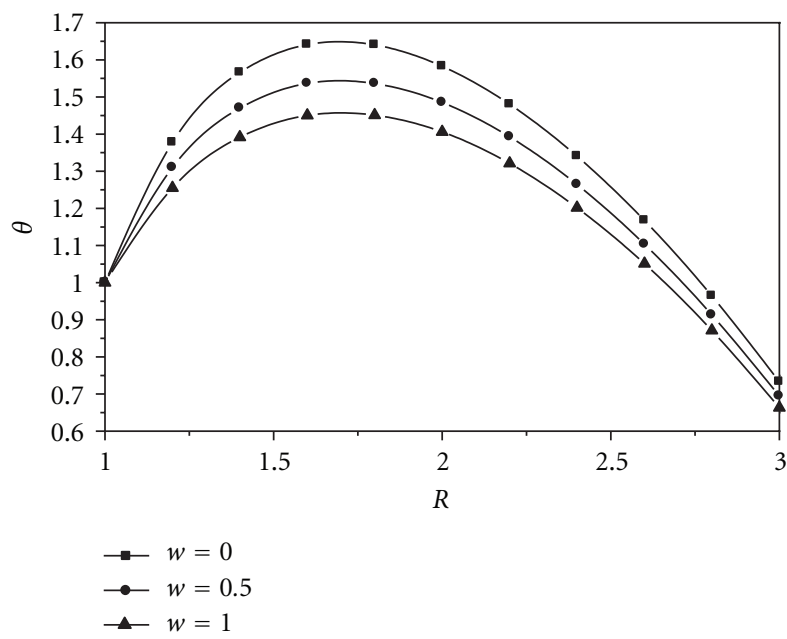

(b)

Figure 4: Temperature distribution ((a) Bi $=0.5$; (b) $\mathrm{Bi}=5$ ). 


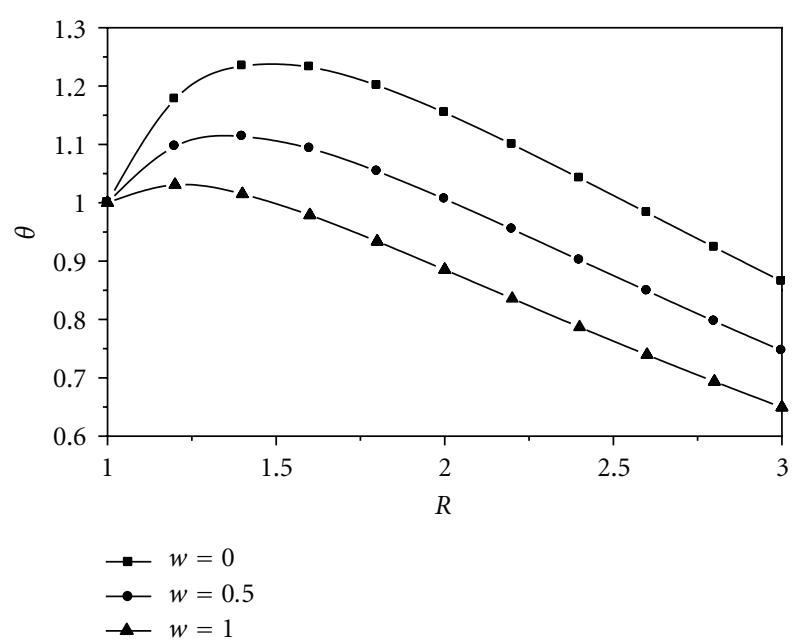

(a)

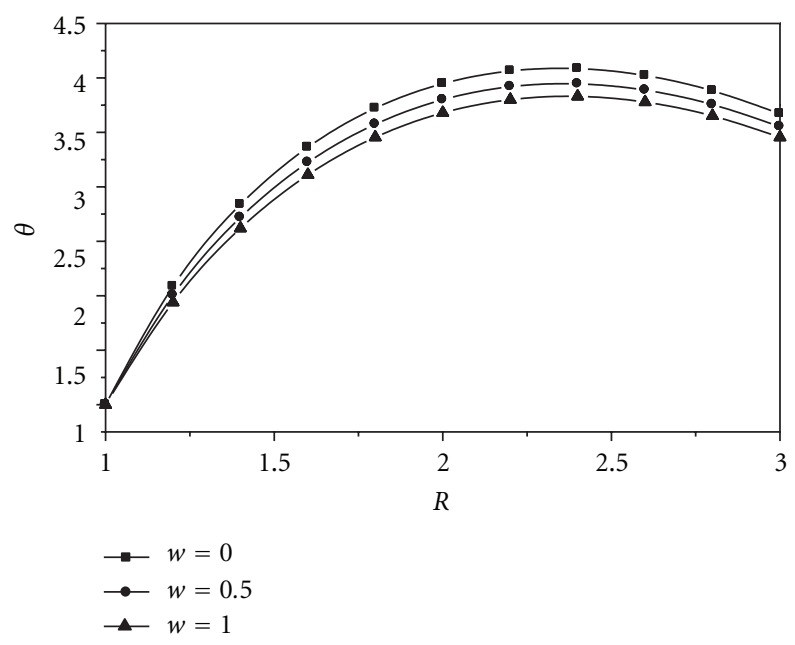

(b)

Figure 5: Temperature distribution ((a) $Q=0$; (b) $Q=2$ ).

\section{Results and Discussion}

Entropy generation of a steady fluid flow with internal heat generation between two rotating cylinders is presented for different parameters. The tangential velocity profiles along the radial direction for the radius ratio $(z) z=2$ and $z=3$ are presented in Figures 2(a) and 2(b), respectively, at different velocity ratio $(w)$ values. The figures show that the velocity decreases as $R$ increases for $w=0$ and $w=0.5$ but the velocity has a minimum value for $w=1$. This minimum velocity can be obtained from the velocity expression given in (7) at $R=[z(z-w) /(w z-1)]^{1 / 2}$. It should be remembered that maximum value of $R$ is equal to $z$ and the value of $w \cdot z$ should always be larger than 1 to insure that such a minimum in velocity exists.

The dimensionless temperature distributions of the rotating fluid as function of $R$ are shown in Figures 3-5 for different set of parameters such as Brinkman number $(\mathrm{Br})$, Biot number (Bi), and dimensionless internal heat

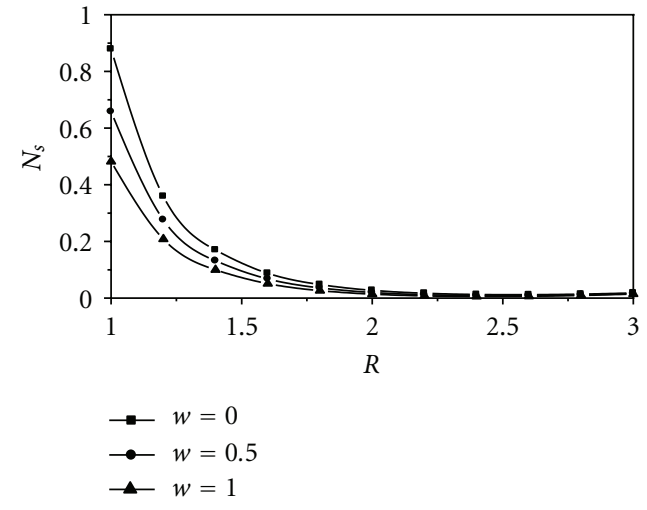

(a)

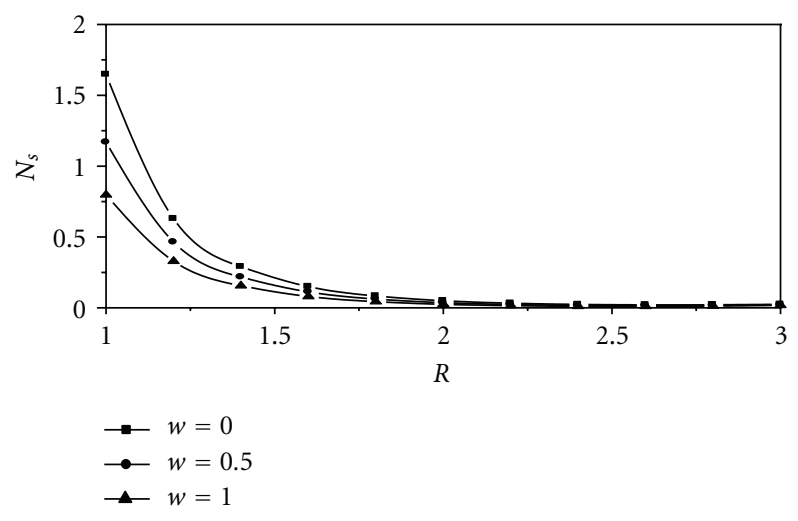

(b)

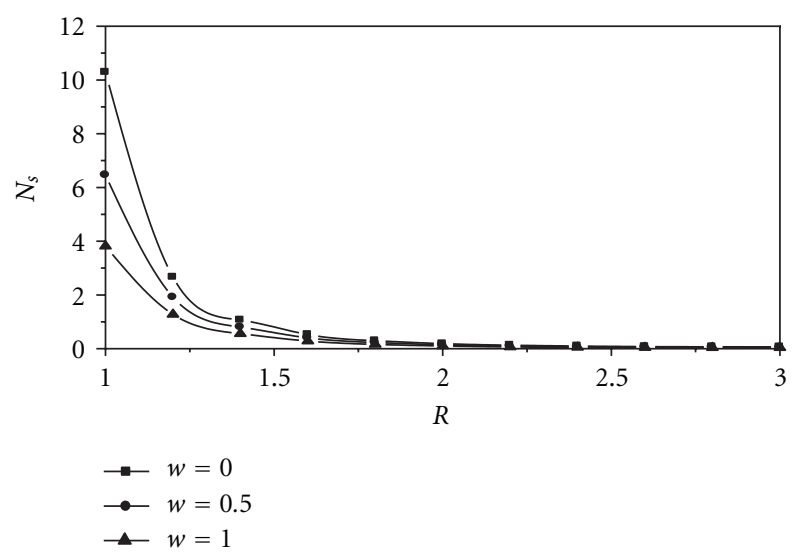

(c)

FIGURE 6: Local entropy generation number distribution ((a) $\mathrm{Br}=$ 0.5 ; (b) $\mathrm{Br}=1$; (c) $\mathrm{Br}=5$ ).

generation $(Q)$ at different velocity ratio $w$ values. Figure 3 shows the effect of Brinkman number on the temperature variation for $Q=1, \mathrm{Bi}=1$, and $z=3$. The figure shows that as Brinkman number increases the temperature increases. The difference between the temperature profiles widens as Brinkman increases, and this difference is very clear in Figure 3(c) for $\mathrm{Br}=5$. In all Figures 3(a)$3(\mathrm{c})$, the temperature has a maximum value at a certain $R$ location. The temperature of the outer rotating fluid surface 


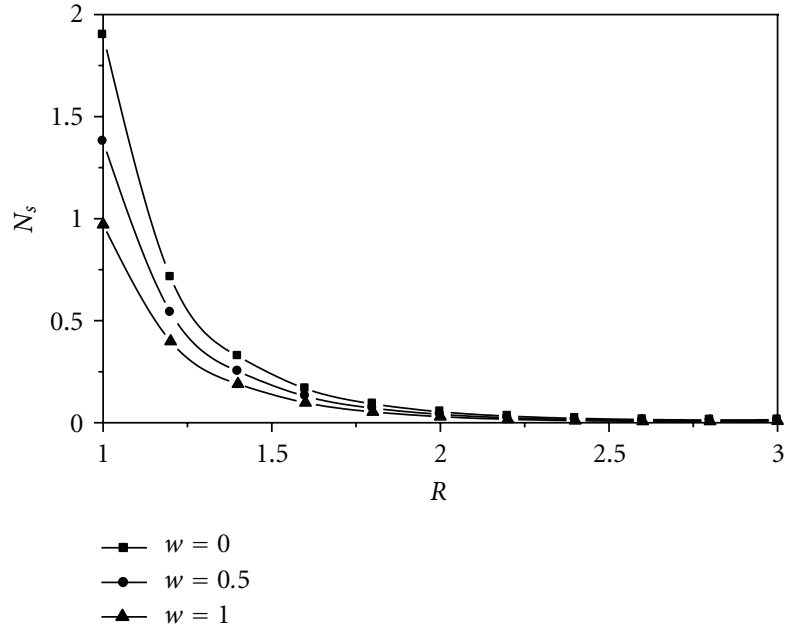

(a)

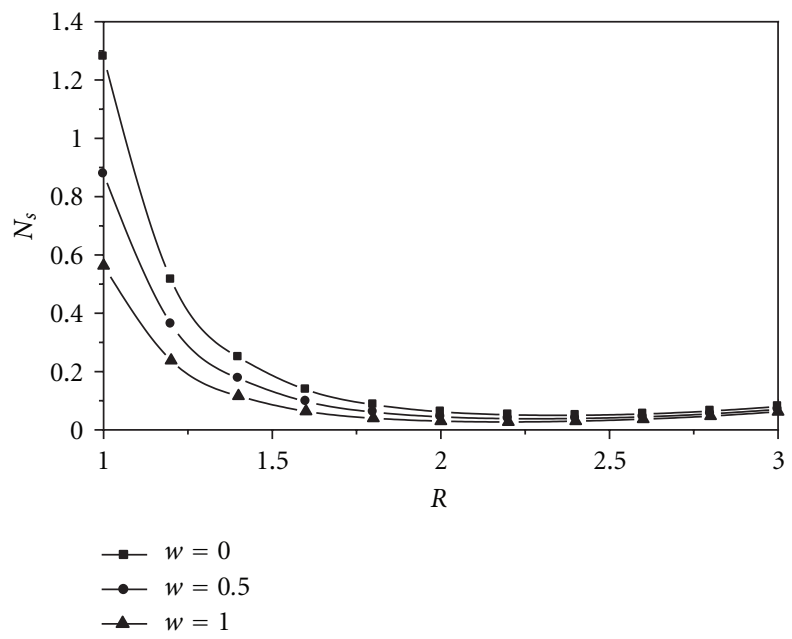

(b)

FIGURE 7: Local entropy generation number distribution ((a) $\mathrm{Bi}=$ 0.5; (b) $\mathrm{Bi}=5$ ).

increases as $w$ decreases for the same $\mathrm{Br}$ and $R$ values but this temperature increases as Brinkman increases for the same $w$ and $R$ values.

The effect of Biot number on the fluid temperature distribution as function of $R$ is given in Figure 4 for $Q=1$, $\mathrm{Br}=1$, and $z=3$. It is shown in Figure 4 that an increase in Biot number results in a decrease in fluid temperature at the outer surface due to better convection cooling. In Figure 4, the fluid temperature has a maximum value for all $w$ and $\mathrm{Bi}$ values considered in this study. This maximum temperature is closer to the outer surface at lower Biot number due to the lower heat convection to the surroundings. When Biot number increases in more heat will be transferred to the surroundings resulting in a higher fluid temperature gradient at the outer fluid surface as can be seen in Figures 4(a) and 4(b). The maximum temperature is shifted closer to the inner surface as Biot number increases.

The maximum temperature is an important factor because the contribution of thermal effect on entropy

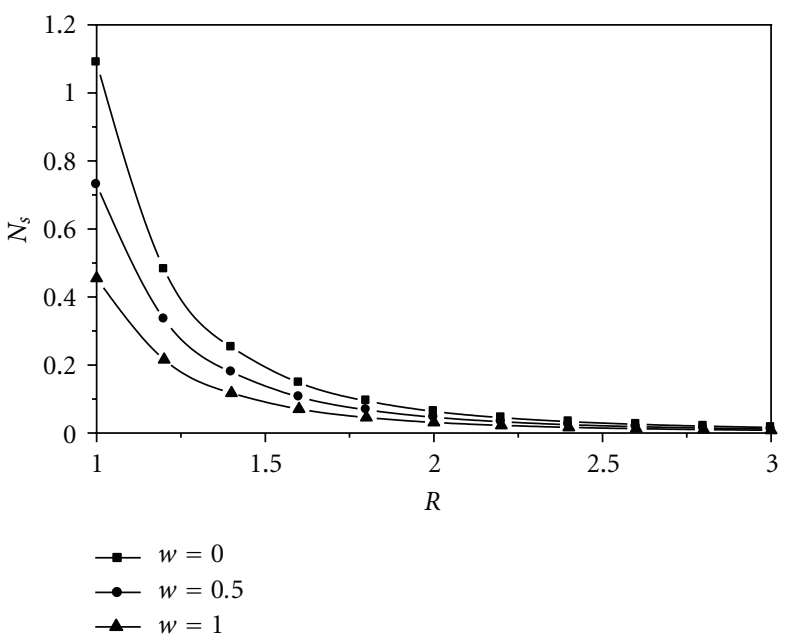

(a)

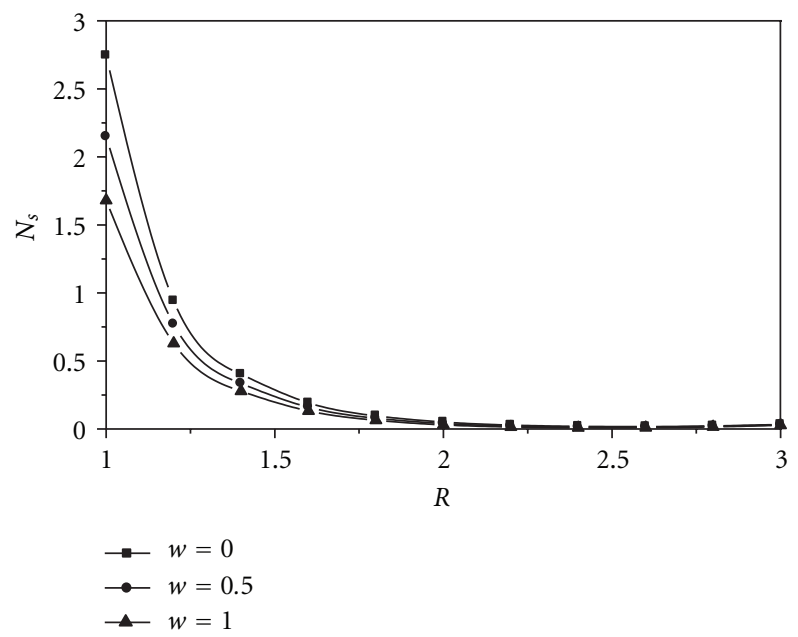

(b)

FIGURE 8: Local entropy generation number distribution ((a) $Q=$ 0 ; (b) $Q=2$ ).

generation will be equal to zero at that maximum value. Figures 5(a) and 5(b) show the temperature distribution for the case with no internal heat generation $(Q=0)$ and with internal heat generation $(Q=2)$, respectively, for $\mathrm{Bi}=1$, $\mathrm{Br}=1$, and $z=3$. It is shown in Figure 5(b) that the internal heat generation results in higher fluid temperature. The maximum temperature value is reached at higher $R$ value (closer to the outer surface) as $Q$ increases.

The variations of local entropy generation number $N_{s}$ with $R$ are shown in Figures 6-8 for the same set of parameters considered in Figures 3-5. Figures 6(a) and 6(c) correspond to Figures 3(a) and 3(c), Figures 7(a) and 7(b) correspond to Figures 4(a) and 4(b), and Figures 8(a) and 8 (b) correspond to Figures 5(a) and 5(b). Figure 9 shows the effect of the temperature ratio $t$ on the local entropy generation number for $Q=1, \mathrm{Br}=1, \mathrm{Bi}=1$, and $z=3$. Figures $6-9$ show that the local entropy generation number decreases to reach a minimum value at a certain $R$ location and then increases very slowly as the outer surface 


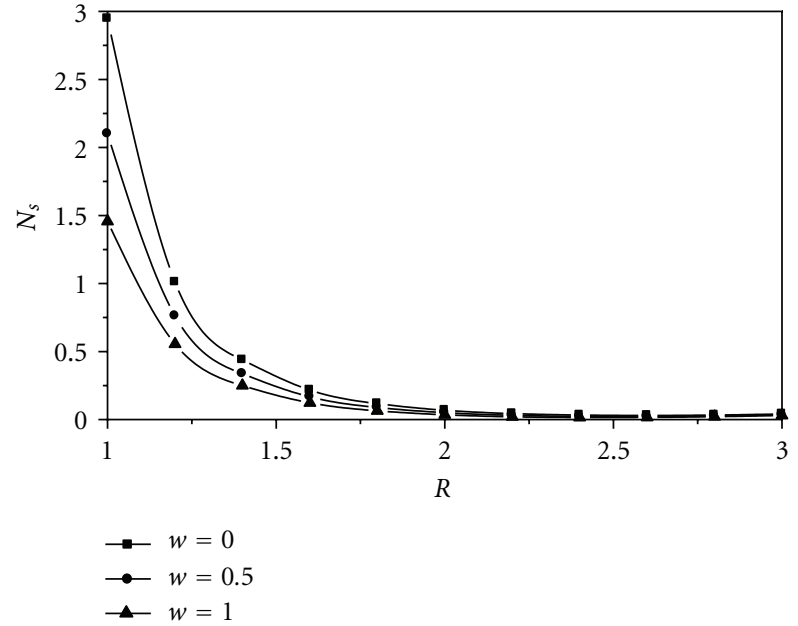

(a)

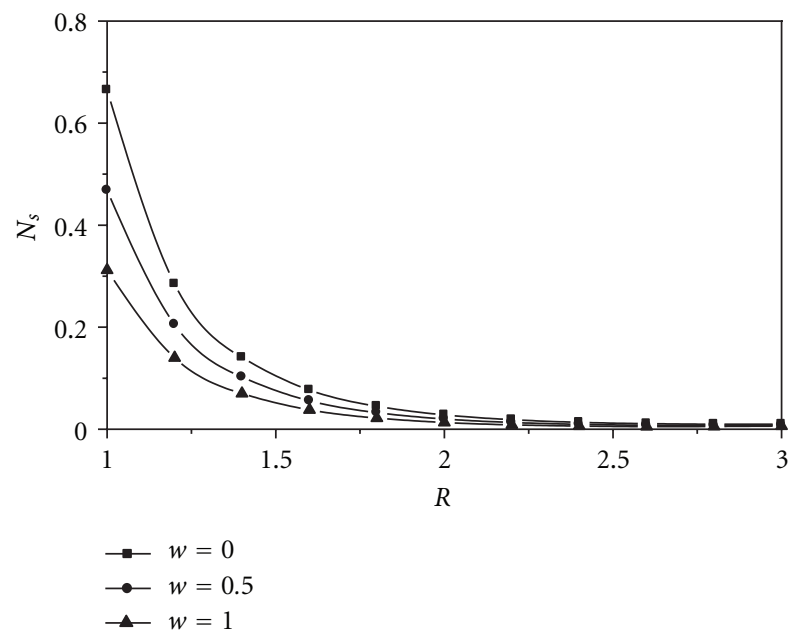

(b)

Figure 9: Local entropy generation number distribution ((a) $t=$ 0.7 ; (b) $t=0.9$ ).

is approached. It can be seen from (19) that even if we have maximum temperature and minimum velocity at the same $R$ location, this will not result in zero entropy generation, that is, $N_{s}=(\mathrm{Br} /(\theta+t /(1-t)))[V / R]^{2}$.

Figures 6-9 also show that the effect of $w$ on local entropy generation number is higher at the inner fluid surface and this effect vanishes as the outer surface is reached. The total entropy generation variations with $w$ are shown in Figures 10-13 for different set of parameters. Figure 10 corresponds to Figure 6, Figure 11 corresponds to Figure 7 except one more case for $\mathrm{Bi}=1$ is added, and Figure 12 corresponds to Figure 8 except one more case for $Q=1$ is added. Figure 13 corresponds to Figure 9 except one more case for $t=0.8$ is added. It is shown in these figures that increasing Brinkman number results in an increase in the total entropy generation, increasing Biot number results in a decrease in the total entropy generation, decreasing internal heat generation yields in lower total entropy generation, and decreasing temperature ratio value $t$ results in an increase in

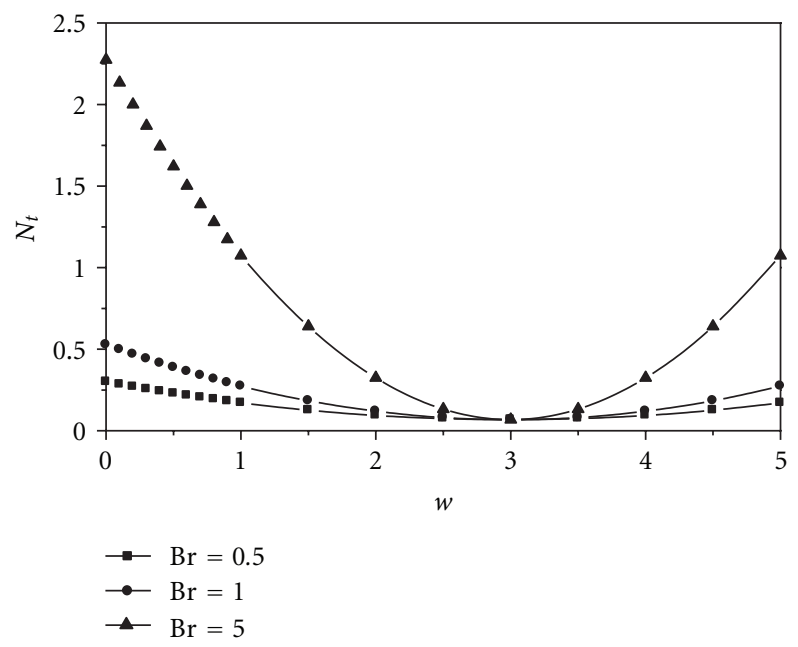

FIGURE 10: Effect of Br on dimensionless total entropy generation rate.

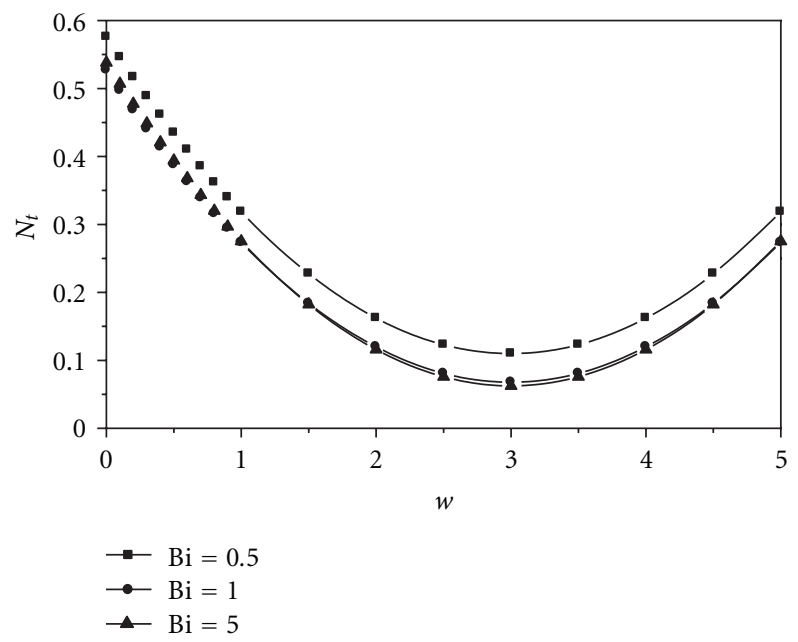

FIGURE 11: Effect of Bi on dimensionless total entropy generation rate.

the total entropy generation. Figures $10-13$ show that there exists a minimum total entropy generation for all the set of parameters considered in this study and this minimum occurs at $w=3$.

\section{Conclusions}

A mathematical model of a fluid with internal heat generation between two rotating cylinders has been developed for velocity, temperature, local entropy generation rate, and total entropy generation rate. It has been proved that the local and the total entropy generation rates have minimum values for all the parameters considered in this work. It is concluded that decreasing Brinkman number, increasing Biot number, decreasing the internal heat generation, and increasing the temperature ratio $t$ result in lower total entropy generation 


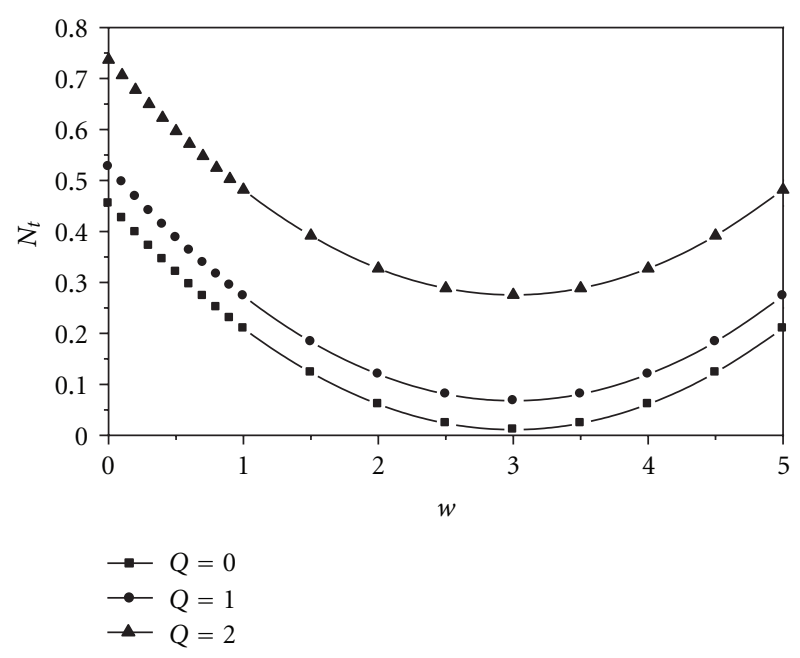

Figure 12: Effect of $Q$ on dimensionless total entropy generation rate.

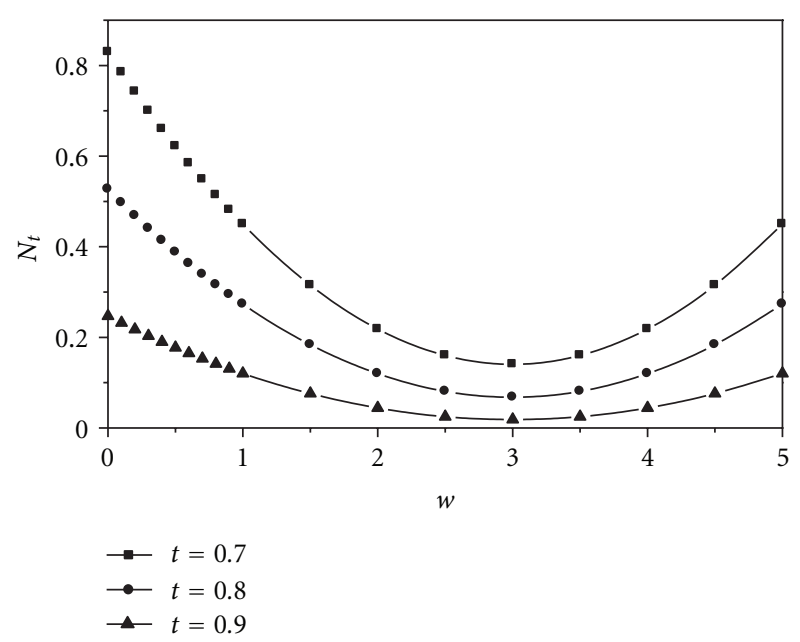

FIGURE 13: Effect of $t$ on dimensionless total entropy generation rate.

rate. It is believed that the results of this study will be of great importance in engineering applications.

\section{Nomenclature}

A: Cross-sectional area $\left(\mathrm{m}^{2}\right)$

Bi: Biot number

Br: Brinkman number

$c_{p}$ : Specific heat capacity $\left(\mathrm{J} \cdot \mathrm{kg}^{-1} \cdot \mathrm{K}^{-1}\right)$

$C_{1}$ : Constant (15)

$C_{2}$ : Constant (16)

D: Constant (17)

Ec: Eckert number

$L: \quad$ Cylinder length (m)

$N_{s}$ : Entropy generation number

$N_{t}$ : Dimensionless total entropy generation rate

$\dot{q}$ : Internal heat generation $\left(\mathrm{W} \cdot \mathrm{m}^{-3}\right)$
Q: Dimensionless internal heat generation

Pr: Prandtl number

$r$ : Radial distance $(\mathrm{m})$

$R:$ Dimensionless radial distance

$\dot{S}: \quad$ Total entropy generation rate $\left(\mathrm{W} \cdot \mathrm{K}^{-1}\right)$

$\dot{S}^{\prime \prime \prime}$ : Local entropy generation rate $\left(\mathrm{W} \cdot \mathrm{m}^{-3} \cdot \mathrm{K}^{-1}\right)$

$t$ : Temperature ratio

T: Temperature $(\mathrm{K})$

$v$ : Tangential velocity $\left(\mathrm{m} \cdot \mathrm{s}^{-1}\right)$

$V$ : Dimensionless velocity

$w$ : Velocity ratio

$z$ : $\quad$ Radius ratio.

\section{Greek Letters}

$\alpha$ : Convective heat transfer coefficient $\left(\mathrm{W} \cdot \mathrm{m}^{-2} \cdot \mathrm{K}^{-1}\right)$

$\phi$ : Viscous dissipation function (9)

$\lambda$ : Thermal conductivity $\left(\mathrm{W} \cdot \mathrm{m}^{-1} \cdot \mathrm{K}^{-1}\right)$

$\mu$ : Dynamic viscosity $\left(\mathrm{kg} \cdot \mathrm{m}^{-1} \cdot \mathrm{s}^{-1}\right)$

$\theta$ : Dimensionless temperature

$\omega$ : Angular velocity $\left(\mathrm{rad} \cdot \mathrm{s}^{-1}\right)$.

\section{Subscripts}

1: Inner cylinder surface

2: Outer cylinder surface

$\infty$ : Coolant at the outer cylinder surface.

\section{References}

[1] M. D. Spasojević, M. R. Janković, and D. D. Djaković, "A new approach to entropy production minimization in diabatic distillation column with trays," Thermal Science, vol. 14, no. 2, pp. 317-328, 2010.

[2] M. Nourollahi, M. Farhadi, and K. Sedighi, "Numerical study of mixed convection and entropy generation in the poiseullebenard channel in different angles," Thermal Science, vol. 14, no. 2, pp. 329-340, 2010.

[3] L. Kolsi, A. Abidi, M. N. Borjini, and H. B. Aïssia, "The effect of an external magnetic field on the entropy generation in threedimensional natural convection," Thermal Science, vol. 14, no. 2, pp. 341-352, 2010.

[4] T. H. Ko, "Numerical investigation of laminar forced convection and entropy generation in a helical coil with constant wall heat flux," Numerical Heat Transfer A, vol. 49, no. 3, pp. 257278, 2006.

[5] A. M. Houshang, M. Shahi, and F. Talebi, "Entropy generation due to natural convection in a partially open cavity with a thin heat source subjected to a nanofluid," Numerical Heat Transfer A, vol. 61, no. 4, pp. 283-305, 2012.

[6] H. F. Oztop, "Effective parameters on second law analysis for semicircular ducts in laminar flow and constant wall heat flux," International Communications in Heat and Mass Transfer, vol. 32, no. 1-2, pp. 266-274, 2005.

[7] Y. Varol, H. F. Oztop, and A. Koca, "Entropy generation due to conjugate natural convection in enclosures bounded by vertical solid walls with different thicknesses," International Communications in Heat and Mass Transfer, vol. 35, no. 5, pp. 648-656, 2008.

[8] H. F. Öztop, I. Dağtekin, and A. Z. Şahin, "Second law analysis of fully developed laminar flow for rectangular ducts with 
semicircular ends," International Communications in Heat and Mass Transfer, vol. 36, no. 7, pp. 725-730, 2009.

[9] B. S. Yilbas, "Entropy analysis of concentric annuli with rotating outer cylinder," Exergy an International Journal, vol. 1, pp. 60-66, 2001.

[10] H. Hamakawa, H. Mori, M. Iino, M. Hori, M. Yamasaki, and T. Setoguchi, "Experimental study of heating fluid between two concentric cylinders with cavities," Journal of Thermal Science, vol. 17, no. 2, pp. 175-180, 2008.

[11] M. Mirzazadeh, A. Shafaei, and F. Rashidi, "Entropy analysis for non-linear viscoelastic fluid in concentric rotating cylinders," International Journal of Thermal Sciences, vol. 47, no. 12, pp. 1701-1711, 2008.

[12] N. A. Roschina, A. V. Uvarov, and A. I. Osipov, "Natural convection in an annulus between coaxial horizontal cylinders with internal heat generation," International Journal of Heat and Mass Transfer, vol. 48, no. 21-22, pp. 4518-4525, 2005.

[13] M. S. Tshehla and O. D. Makinde, "Analysis of entropy generation in a variable viscosity fluid flow between two concentric pipes with convective cooling at the surface," International Journal of Physical Sciences, vol. 6, no. 25, pp. 6053-6060, 2011.

[14] S. Mahmud and R. A. Fraser, "Analysis of entropy generation inside concentric cylindrical annuli with relative rotation," International Journal of Thermal Sciences, vol. 42, no. 5, pp. 513-521, 2003.

[15] M. E. H. Assad, "Effect of maximum and minimum heat capacity rate on entropy generation in a heat exchanger," International Journal of Energy Research, vol. 34, no. 14, pp. 1302-1308, 2010.

[16] O. D. Makinde and A. Aziz, "Second law analysis for a variable viscosity plane Poiseuille flow with asymmetric convective cooling," Computers and Mathematics with Applications, vol. 60, no. 11, pp. 3012-3019, 2010.

[17] E. M. A. Mokheimer and A. H. Al-Salim, "Entropy generation due to mixed convection between vertical parallel plates under isothermal boundary conditions," International Journal of Exergy, vol. 6, no. 5, pp. 671-697, 2009.

[18] M. El Haj Assad, "Entropy generation analysis in a slab with non-uniform heat generation subjected to convection cooling," International Journal of Exergy, vol. 9, no. 3, pp. 355369, 2011.

[19] A. Bejan, Entropy Generation Minimization, CRC Press, Boca Raton, Fla, USA, 1996. 

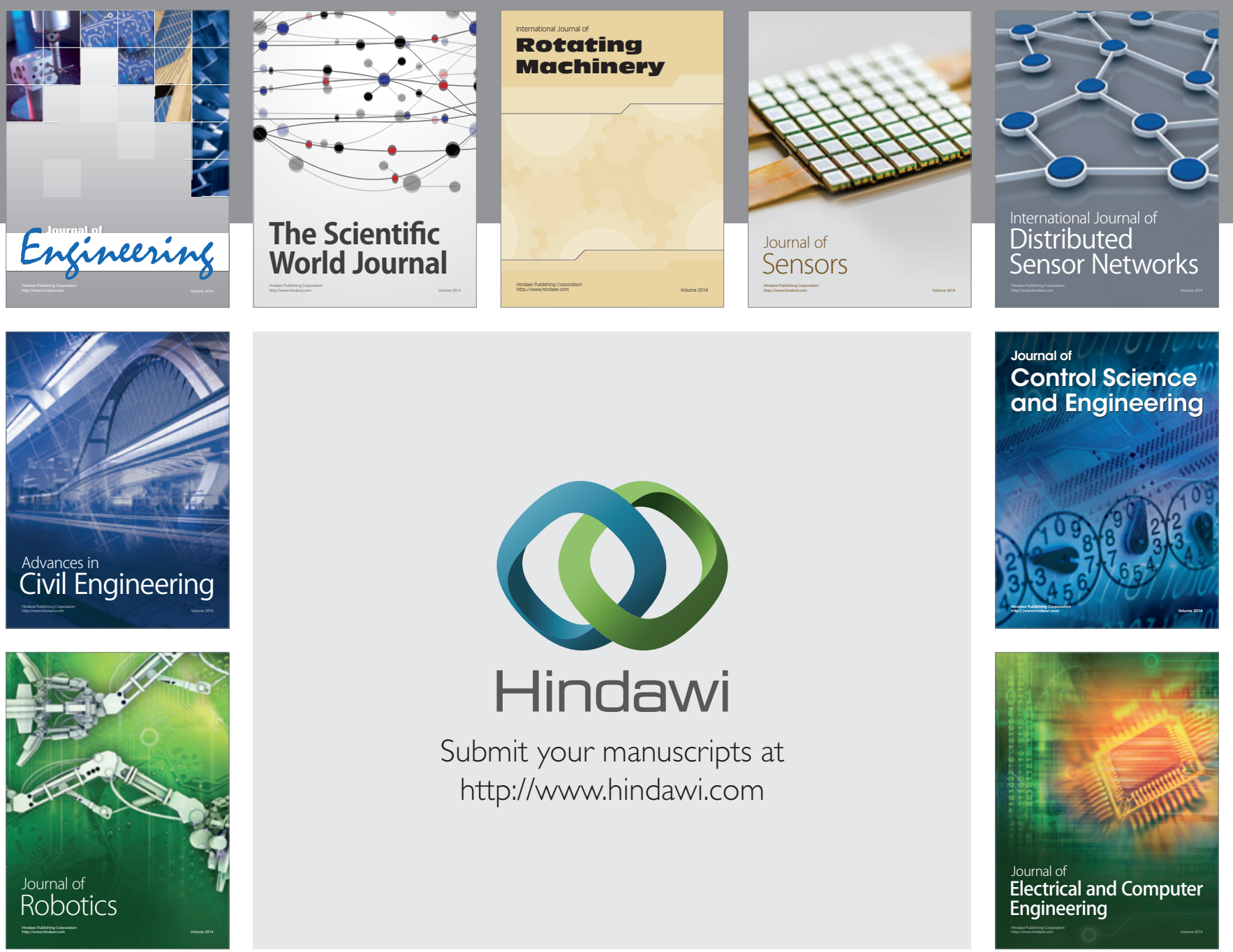

Submit your manuscripts at

http://www.hindawi.com
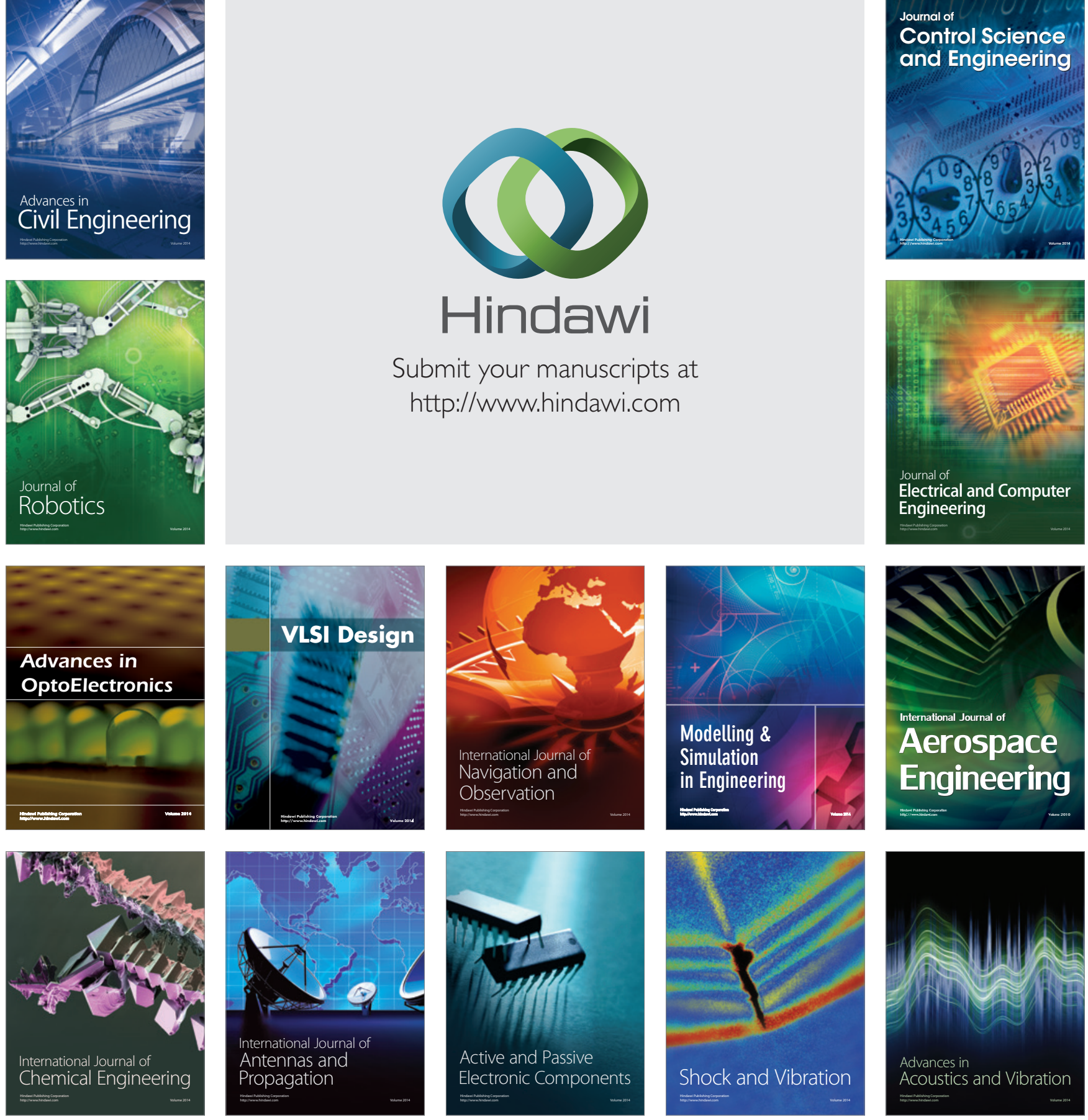